\title{
Erratum zu: Das Bestellerprinzip auf Wohnungs- und Immobilienmärkten - ist gut gemeint auch gut?
}

\author{
Jochen Michaelis • Benjamin Schwanebeck
}

Online publiziert: 6. Juli 2021

(C) Der/die Autor(en) 2021

\section{Erratum zu:}

\section{List Forum 2020}

https://doi.org/10.1007/s41025-020-00198-w

\section{Der Artikel}

Das Bestellerprinzip auf Wohnungs- und Immobilienmärkten - ist gut gemeint auch gut?

Jochen Michaelis · Benjamin Schwanebeck

wurde ursprünglich ohne „Open Access“ Online First auf der Internetplattform des Verlags publiziert. Nach der Veröffentlichung im Band 46 Heft 2 pp 227-244 entschieden sich die Autoren nachträglich für eine „Open Access“-Veröffentlichung. Das Urheberrecht des Artikels wurde deshalb zu (c) Der/die Autor(en) 2020 geändert.

Funding Open Access funding enabled and organized by Projekt DEAL.

Open Access Dieser Artikel wird unter der Creative Commons Namensnennung 4.0 International Lizenz veröffentlicht, welche die Nutzung, Vervielfältigung, Bearbeitung, Verbreitung und Wiedergabe in jeglichem Medium und Format erlaubt, sofern Sie den/die ursprünglichen Autor(en) und die Quelle ordnungsgemäß nennen, einen Link zur Creative Commons Lizenz beifügen und angeben, ob Änderungen vorgenommen wurden.

Die Online-Version des Originalartikels ist unter https://doi.org/10.1007/s41025-020-00198-w zu finden.

Jochen Michaelis $(\bowtie)$

Institut für Volkswirtschaftslehre, Universität Kassel, Nora-Platiel-Str. 4, 34109 Kassel, Deutschland

E-Mail: jomichae@uni-kassel.de

Benjamin Schwanebeck

Lehrstuhl für Volkswirtschaftslehre, FernUniversität in Hagen, Universitätsstr. 47, 58097 Hagen,

Deutschland

E-Mail: benjamin.schwanebeck@fernuni-hagen.de 
Die in diesem Artikel enthaltenen Bilder und sonstiges Drittmaterial unterliegen ebenfalls der genannten Creative Commons Lizenz, sofern sich aus der Abbildungslegende nichts anderes ergibt. Sofern das betreffende Material nicht unter der genannten Creative Commons Lizenz steht und die betreffende Handlung nicht nach gesetzlichen Vorschriften erlaubt ist, ist für die oben aufgeführten Weiterverwendungen des Materials die Einwilligung des jeweiligen Rechteinhabers einzuholen.

Weitere Details zur Lizenz entnehmen Sie bitte der Lizenzinformation auf http://creativecommons.org/ licenses/by/4.0/deed.de. 